\title{
ESCOLA E PROGRAMA NA EDUCAÇÃO INTEGRAL: ABORDAGENS E SINGULARIDADES
}

\author{
DENISE DE ALMEIDA OSTLER
}

\begin{abstract}
RESUMO
O presente artigo traz como tema a "educação integral",pautando-se em uma discussão sobre as nomenclaturas "escola de tempo integral" e "programa ensino integral"etendo por objetivo discutir os seus aspectos peculiares ediversidades, bem como refletir a respeito das singularidades e divergências apontadas na construção de uma proposta de"escola de tempo integral",implantada pela Secretaria de Estado da Educação do Estado de São Paulo, em 2006, e o"programa ensino integral", efetivado no ano de 2012, em São Paulo, pela mesma Secretaria, uma vez que ambas as propostas contemplam a educação integral. As abordagens aqui expostas fazem parte de um trabalho de pesquisa de doutorado, a partir do estudo desenvolvido sob o título:"O impacto da implantação do programa ensino integral no atendimento a alunos com deficiência: desdobramentos em duas escolas públicas da Baixada Santista". Para tanto, recorremos a autores como: Ribeiro (1988); Paro (1988); Teixeira (1999); Guará (2007); Padilha (2010), entre outros, como também à legislação que norteia a "educação integral". Considerando a importância da "educação integral” para a formação global do indivíduo,cabe-nos não só refletir acerca das diferenças exibidas entre os modelos de ensino,da "escola de tempo integral" e o do "programa ensino integral",mas salientar ser desnecessária a existência diferenciada de ambas as propostas.
\end{abstract}

Palavras-chave: 1.Ensino Integral-escola.2.Programa ensino integral.3.Políticas Públicas. 


\title{
INTEGRATED LEARNING PROGRAMME AND SCHOOLS: APPROACHES AND SINGULARITIES
}

\begin{abstract}
This study focuses on the theme of "integrated learning" and is based on the discussion about the different nomenclature, "full-time education" and "integrated curriculum". It aims at examining peculiarities and diversities, as well as reflecting on singularities and divergences in designing the proposal for a "full-time education" school programme, implemented by the Secretary of Education in São Paulo, in 2006, and the integrated curriculum, implemented in 2012, by the same Secretary, once both proposals address "integrated learning". The approaches used in this study are part of a doctoral research under the title: "The Impact of the implementation of an Integrated Learning Programme for impaired students: developments in two public schools in Santos,São Paulo". The study used as reference authors like: Ribeiro (1988); Paro (1988); Teixeira (1999); Guará (2007); Padilha (2010), amongst others, as well, as the current legislation that guides "integrated learning" programmes. Taking into consideration the importance of "integrated learning" for the global development of an individual person, our responsibility is, not only to reflect upon the differences between the "full-time education" and the "integrated curriculum" teaching models, but also to highlight the fact that the existence of a differentiated approach to each proposal is unnecessary.
\end{abstract}

Keywords: 1. Integrated Learning-School.2. Integrated Curriculum. 3. Public policies.

\section{INTRODUÇÃO}

$\mathrm{Na}$ atualidade, ainda é possível observar uma diversidade no trato conceitual do que se nomina por "escola de tempo integral e programa ensino integral", mesmo considerando que ambas têm como objetivo ao que se supõe, a permanência do aluno na escola, em tempo integral, dando atendimento não só à informação, como também à formação, isto é, a uma educação global com diferentes possibilidades de ensino e a maior 
abrangência possível a todos os indivíduos, indistintamente. Tal temática foi pesquisada na tese de doutorado desenvolvida sob o título: "O impacto da implantação do programa ensino integral no atendimento a alunos com deficiência: desdobramentos em duas escolas públicas da Baixada Santista”.

As observações a respeito das questões levantadas não só do ponto de vista terminológico, mas também epistemológico, levaram-nos a dedicar um dos capítulos da tese a essa discussão, da qual trazemos, para este artigo, alguns pontos que sinalizam diferenças importantes entre um e outro modelo de ensino, tendo como foco a questão: se a proposta da Secretaria de Estado da Educação é a de oferecer uma educação integral "paratodos", por que estabelecer dualidade curricular e pedagógica entre os modelos que constituem o Ensino Integral?

O interesse em aprofundar os estudos sobre o tema justifica-se pela necessidade de demonstrar que a educação integral está voltada para um ensino integral e a formação do aluno por inteiro.

Para tanto, partimos da compreensão do termo "integral" para relacionarmos a ele aspectos da visão de educação e de ensino, na tentativa de apresentar a construção de propostas ora vigentes pela Secretaria da Educação do Estado de São Paulo. Tomamos como referenciais as produções de: Paro (1988); Teixeira (1994,1959); (2006); Guará (2006), entre outros.

Apesar da amplitude das reflexões que a temática exige além das aqui apresentadas, considerando a natureza deste artigo, reafirmamos a importância de trazer essa temática à discussão, no sentido de ampliar visibilidade de aspectos pertinentes e que merecem consideração na atualidade.

\section{ALGUNS ASPECTOS HISTÓRICOS SOBRE A EDUCAÇÃO INTEGRAL}

Por definição, o termo "integral" foi utilizado no sentido de dar atendimento às pessoas, levando-se em conta "todas" as dimensões do desenvolvimento humano, ao mesmo tempo em que se caracteriza como processo ao longo de toda a vida. A “educação integral"não é uma modalidade de educação, mas a sua própria definição. 
Quando nos referimos à Educação Integral, estamos falando de uma educação que trabalha pelo atendimento e pelo desenvolvimento integral do educando nos aspectos biológicos, psicológicos, cognitivos, comportamentais, afetivos, relacionais, valorativos, sexuais, éticos, estéticos, criativos, artísticos, ambientais, políticos, tecnológicos e profissionais (ANTUNES, PADILHA, 2010, p.17).

O que se quer enfatizar é que a referência à educação integral remete a uma educação que permite o desenvolvimento da pessoa integralmente, isto é, que considere todos os seus aspectos, conforme novamente destacam Antunes e Padilha (2010):

[...] Educação Integral não é a mesma coisa que tempo integral ou horário integral. Ela também não se refere apenas a determinados espaços ou tempos de aprendizagem, como se a educação tivesse que acontecer apenas dentro dos calendários fixos, seriados ou ciclos, e, menos ainda, apenas no âmbito da escola. Quando nos referimos à Educação Integral, além das dimensões da formação humana citadas acima, estamos tratando de abrir a mente e o coração para as diferentes possibilidades de ensino e de aprendizagem que formos capazes de realizar. Trata-se de articularmos saberes a partir de projetos integrados e integradores, de ações e parcerias intersetores e interculturas.

[...] A Educação Integral é, na verdade, fundamento do Tempo Integral, pois é a partir do estudo dos seus princípios e diretrizes que melhor podemos desenvolver uma experiência escolar ou comunitária de horário ou de tempo integral, aumentando a jornada de permanência dos alunos nas instituições educacionais onde elas estudam ou desenvolvem atividades diversas - culturais, esportivas, de lazer, etc. (ANTUNES; PADILHA, 2010, p.18).

Em consonância ao que afirmam Antunes e Padilha (2010), consideramos que para se formar o homem integralmente não basta apenas a escolaridade formal, normal, é necessário que 
seja oferecida uma formação ampla e profunda, com tarefas diferenciadas e que os alunos inseridos nesse contexto, possam adquirir conhecimentos em outras áreas e não somente naquelas constantes do currículo comum.

No sentido de alargar a compreensão conceitual da educação integral, recorremos à contribuição de John Dewey (1959), ao alertar para a cisão existente nos sistemas de ensino, entre a vida e a escola. Para esse pensador, a escola não deveria ser uma preparação para a vida, mas o momento de escolarização visto como parte da própria vida. Dewey considerava a vivência na comunidade escolar como uma etapa privilegiada de compreensão da vida em sociedade, ainda que em uma escala menor, para então, possibilitar a compreensão da sociedade em escalas maiores e mais complexas (DEWEY, 1959).

Dessa forma, este estudo apoia-se em autores que discutem e defendem a educação integral, como:Ribeiro (2000); Paro (1988); Teixeira (1994,1959); Pacheco (2006); Guará (2006); Antunes, Padilha (2010), entre outros. Incluem-se, nesta discussão, fundamentos em bases legais, com destaque para a legislação que norteia o ensino integral, com o intuito de oferecer dados concisos e vigentes.

Para melhor elucidar as propostas pedagógicas estabelecidas entre a "Escola de Tempo Integral" e o "Programa Ensino Integral" apresentamos, a seguir, as peculiaridades existentes entre ambas as propostas.

\section{A ESCOLA DE TEMPO INTEGRAL (ETI) E SUAS PECULIARIDADES}

No Brasil, particularmente nas décadas de 1920 e 1930, o pensamento educacional foi marcado por concepções de uma educação integral. O sentido de educação integral remetia a uma educação escolar ampliada em relação às suas tarefas culturais e sociais. A proposta de uma educação integral refletia o desejo de formar o homem integral (SÃO PAULO. Secretaria da Educação do Estado de São Paulo. Escola de tempo integral, 2007, p.5).

$\mathrm{Na}$ década de 1950, o educador Anísio Teixeira realizou experiências educacionais criando no Estado da Bahia, o Centro 
Educacional Popular, passando mais tarde a se chamar Centro Educacional Carneiro Ribeiro - Escola Parque, erguido no bairro da Liberdade - Salvador/Bahia, por ser um dos bairros mais populosos de Salvador, e com uma demanda considerável de alunos carentes e defasados por idade e série. Tratava-se de um complexo dotado de quatro escolas-classe, sendo que apenas três foram construídas para abrigar mil alunos cada, e uma escola-parque, com a capacidade para abrigar quatro mil alunos, cujos pavilhões foram sendo construídos lentamente, com o auxílio do INEP. Seu funcionamento se dava em dois turnos conjugados, de modo que o aluno pudesse desfrutar de um dia completo de educação, onde recebia a educação formal em meio período, manhã ou tarde, e a educação social, em outro período, oferecida na escola-parque, onde os jovens desenvolviam atividades extraclasses de educação física, jogos, recreação, biblioteca, teatro de arena e atividades ligadas aos setores de socialização e artística. A finalidade última era oferecer uma formação integral.

No Complexo Educacional, o alunopodia contar com atendimento à saúde e à alimentação regular, alimentação essa que, para muitos, consistia na única refeiçãodo dia. Nas palavras de Anísio Teixeira, a escola-classe representava:

[...] uma escola parcial e para funcionar em turnos. Mas virá integrá-la, a escola-parque. A criança fará um turno na escola-classe e um segundo turno na escola-parque. Nesta escola, além de locais para suas funções específicas, temos mais a biblioteca infantil, os dormitórios para 200 das 4.000 crianças atendidas pelo Centro e os serviços gerais e de alimentação. [...] A criança, pois, terá um regime de semi-internato, recebendo educação e assistência alimentar. Cinco por cento dentre elas receberão mais o internato. Serão as crianças chamadas propriamente de abandonadas, sem pai nem mãe, que passarão a ser não as hóspedes infelizes de tristes orfanatos, mas as residentes da escola-parque, às quais competirá a honra de hospedar as suas colegas, bem como a alegria de frequentar, com elas, as escolas-classe (TEIXEIRA, 1959). 
Registram-se também no Estado de São Paulo, na década de 1970, significativas experiências resultantes de programas e projetos educacionais desenvolvidos pelasEscolas Comunitárias (anos de 1970) e pelo Programa de Formação Integral da Criança (PROFIC), nos anos de 1980.

Pouco depois, na década de 1980, o Programa de Formação Integral da Criança (PROFIC), gestado na UNICAMP, em 1987, mais tarde foi incorporado pela Secretaria de Educação do Estado de São Paulo e, posteriormente transformado em "Programa de Governo".

Ainda na década de 1980 - entre 1984 e 1987, a educação integral foi introduzida em outros Estados, a exemplo do Rio de Janeiro, num programa que buscou inspiração nas ideias de Anísio Teixeira. Tratava-se da implantação dos Centros Integrados de Educação Pública (CIEP), pelo governo de Leonel Brizola, sob a coordenação de Darcy Ribeiro. Seu objetivo declarado era operar uma revolução no sistema educacional capaz de diminuir os altos índices de evasão e repetência (MIGNOT, 2001, p. 155).

$\mathrm{Na}$ análise da equipe responsável pela educação, o quadro de abandono da escola pública só poderia ser revertido pela expansão da rede física, pela revisão de objetivos e metodologias, pelo fornecimento de materiais didáticos a professores e alunos, pelo provimento de assistência médica e nutricional. Porém, ampliar a rede física escolar foi entendido como criar uma nova escola para novos tempos. A nova proposta de trabalho pedagógico implicava, ao lado das atividades de estudo, também a priorização das atividades ligadas à saúde, à nutrição e ao esporte (MIGNOT, 2001, p. 157).

No Estado de Minas Gerais, uma das escolas de tempo integral a ressaltar foi a Escola Estadual Pedro Dutra, localizada no bairro Padre Eustáquio, em Belo Horizonte. Outra escola de tempo integral que também obteve destaque foi a do Estado do Rio Grande do Sul, voltada à educação formal/rural, situada no 
Distrito de Pedreiras da Airosa Galvão, município de Arroio Grande/RS. ${ }^{1}$

No final do ano de 2005, a "Escola de Tempo Integral" (ETI) foi implementada na rede pública do Estado de São Paulo, seu processo de funcionamento foi iniciado em 2006, envolvendo 508 escolas de ensino fundamental, representando $9 \%$ do total das unidades, considerando que a rede estadual contava com 5.598 escolas (SÃO PAULO. Secretaria da Educação do Estado de São Paulo. Escola de tempo integral, 2007, p.3).

Instituído pela Resolução SE-SP n. 89 de 09/12/2005, o projeto da "Escola de Tempo Integral" (ETI), inicialmente criado para atender à demanda do ensino fundamental (ciclos I e II), tinha por objetivo prolongar a permanência dos alunos na escola pública estadual, de modo a ampliar as possibilidades de aprendizagem, com o enriquecimento do currículo básico, a exploração de temas transversais e a vivência de situações que favorecessem o aprimoramento pessoal, social e cultural, com uma jornada de nove (9) horas diárias, perfazendo um total de 45 horas semanais. Os alunos cursavam aulas e oficinas em dois períodos. No primeiro período, assistiam aulas referentes às disciplinas do currículo básico (disciplinas da Base Nacional Comum), e, no segundo período, o currículo era enriquecido com procedimentos metodológicos inovadores (oficinas curriculares) envolvendo atividades de linguagem e de matemática; atividades artísticas; atividades esportivas e motoras; atividades de participação social e orientação para estudos e pesquisas, conforme quadros apresentados a seguir.

Os dados referentes à Escola de Educação Formal/Rural do Estado do Rio Grande do Sul foram extraídos do texto: Desafios da Escola do Campo: Educação Integral/Tempo Integral, apresentado no V Encontro de Grupos de Pesquisa "Agricultura e Desenvolvimento Regional e Transformações socioespaciais", realizado entre 25 e 27 de novembro de 2009, de autoria de LUCAS, Rosa Elaine Antonia, doutora em Ciências, professora do Departamento de Geografia/ICH/UFPel e WIZNIEWSKY,José Geraldo,doutor em Agronomia e professor do DEAER/CCR/UFSM. 
Quadro 1.Matriz Curricular da Escola de Tempo Integral (ETI) - Ensino Fundamental - Ciclo I

\begin{tabular}{|c|c|c|c|c|c|c|c|}
\hline \multicolumn{8}{|c|}{$\begin{array}{l}\text { ORGANIZAÇÄO DA ESCOLA DE TEMPO INTEGRAL } \\
\text { ENSINO FUNDAMENTAL - CICLOI }\end{array}$} \\
\hline \multirow{2}{*}{$\begin{array}{l}\text { Turno } \\
\text { Horário }\end{array}$} & \multirow{2}{*}{\multicolumn{3}{|c|}{ Componentes Curriculares }} & \multicolumn{4}{|c|}{ Séries/aulas } \\
\hline & & & & $1^{a}$ & $2^{a}$ & $3^{a}$ & $4^{a}$ \\
\hline \multirow{8}{*}{$\begin{array}{l}\text { Manhā } 7 \mathrm{~h} \\
\text { às } 11 \mathrm{~h} 30 \\
\text { Recreio: } \\
20^{\prime}\end{array}$} & \multirow{8}{*}{$\begin{array}{l}\text { Curriculo } \\
\text { Básico }\end{array}$} & \multirow{7}{*}{$\begin{array}{l}\text { Base Nacional } \\
\text { Comum e Parte } \\
\text { Diversificada }\end{array}$} & Lingua Portuguesa & 7 & 7 & 7 & 7 \\
\hline & & & Educação Artistica & 2 & 2 & 2 & 2 \\
\hline & & & Educaçăo Fisica & 2 & 2 & 2 & 2 \\
\hline & & & História & 2 & 2 & 2 & 2 \\
\hline & & & Geografia & 2 & 2 & 2 & 2 \\
\hline & & & Matemática & 7 & 7 & 7 & 7 \\
\hline & & & Cièncias Fis.Biológicas & 3 & 3 & 3 & 3 \\
\hline & & \multicolumn{2}{|l|}{ Total } & 25 & 25 & 25 & 25 \\
\hline \multicolumn{8}{|c|}{ Almoço $-11 \mathrm{~h} 30$ às $12 \mathrm{~h} 30$} \\
\hline \multirow{16}{*}{$\begin{array}{l}\text { Tarde } \\
12 \mathrm{~h} 30 \text { as } \\
16 \mathrm{~h} 10 \\
\text { Recreio: } \\
20^{\prime}\end{array}$} & \multirow{16}{*}{$\begin{array}{l}\text { Oficinas } \\
\text { Curricular } \\
\text { es }\end{array}$} & \multirow{5}{*}{$\begin{array}{l}\text { Orientação } \\
\text { Atividades de } \\
\text { Linguagem e } \\
\text { de Matemática }\end{array}$} & para Estudo e Pesquisa & 2 & 2 & 2 & 2 \\
\hline & & & Hora de Leitura & 3 & 3 & 3 & 3 \\
\hline & & & Experiências Matemáticas & 3 & 3 & 3 & 3 \\
\hline & & & $\begin{array}{l}\text { Lingua Estrang. Moderna- } \\
\text { Inglés }\end{array}$ & 1 & 1 & 1 & 1 \\
\hline & & & Informática Educacional & 2 & 2 & 2 & 2 \\
\hline & & \multirow{4}{*}{$\begin{array}{l}\text { Atividades } \\
\text { Artisticas }\end{array}$} & Teatro & \multirow{4}{*}{3} & \multirow{4}{*}{3} & \multirow{4}{*}{3} & \multirow{4}{*}{3} \\
\hline & & & Artes Visuais & & & & \\
\hline & & & Música & & & & \\
\hline & & & Dança & & & & \\
\hline & & \multirow{3}{*}{$\begin{array}{l}\text { Atividades } \\
\text { Esportivas e } \\
\text { Motoras }\end{array}$} & Esporte & \multirow{3}{*}{3} & \multirow{3}{*}{3} & \multirow{3}{*}{3} & \multirow{3}{*}{3} \\
\hline & & & Ginástica & & & & \\
\hline & & & Jogo & & & & \\
\hline & & \multirow{3}{*}{$\begin{array}{l}\text { Atividades de } \\
\text { Participação } \\
\text { Social }\end{array}$} & $\begin{array}{l}\text { Saúde e Qualidade de } \\
\text { Vida }\end{array}$ & \multirow{3}{*}{3} & \multirow{3}{*}{3} & \multirow{3}{*}{3} & \multirow{3}{*}{3} \\
\hline & & & Filosofia & & & & \\
\hline & & & Empreendedorismo Social & & & & \\
\hline & & \multirow{2}{*}{\multicolumn{2}{|c|}{ Total }} & 20 & 20 & 20 & 20 \\
\hline Total & & & & 45 & 45 & 45 & 45 \\
\hline
\end{tabular}

Fonte: SÃO PAULO. Secretaria da Educação do Estado de São Paulo. CENP. Matriz Curricular da Escola de Tempo Integral. Ensino Fundamental - Ciclo I. In: SE/CENP. Escola de Tempo Integral.Tempo e qualidade, 2007 [apostila]. 
Quadro 2. Matriz Curricular da Escola de Tempo Integral (ETI) - Ensino Fundamental - Ciclo II

\begin{tabular}{|c|c|c|c|c|c|c|c|}
\hline \multicolumn{8}{|c|}{$\begin{array}{l}\text { ORGANIZACAAO DA ESCOLA DE TEMPO INTEGRAL } \\
\text { ENSINO FUNDAMENTAL - CICLO \| }\end{array}$} \\
\hline \multirow{2}{*}{$\begin{array}{l}\text { Turnol } \\
\text { Horário }\end{array}$} & \multirow{2}{*}{\multicolumn{3}{|c|}{ Componentes Curriculares }} & \multicolumn{4}{|c|}{ Séries/aulas } \\
\hline & & & & $5^{\bullet}$ & $6^{a}$ & 7 & $8^{a}$ \\
\hline \multirow{12}{*}{$\begin{array}{l}\text { Manhä } \\
7 \text { hooàs } \\
12 \text { h20 } \\
\text { Recreio: } \\
20^{\prime}\end{array}$} & \multirow{9}{*}{$\begin{array}{l}\text { Curriculo } \\
\text { Básico }\end{array}$} & \multirow{9}{*}{$\begin{array}{l}\text { Base Nacional } \\
\text { Comum } \\
\mathrm{e} \\
\text { Parte } \\
\text { Diversificada }\end{array}$} & Lingua Portuguesa & 6 & 6 & 6 & 6 \\
\hline & & & $\begin{array}{l}\text { Lingua Estrangeira } \\
\text { Moderna-Inglês }\end{array}$ & 2 & 2 & 2 & 2 \\
\hline & & & Educação Artistica & 2 & 2 & 2 & 2 \\
\hline & & & Educação Fisica & 2 & 2 & 2 & 2 \\
\hline & & & História & 3 & 3 & 3 & 3 \\
\hline & & & \begin{tabular}{|l} 
Geografia \\
\end{tabular} & 3 & 3 & 3 & 3 \\
\hline & & & Matemática & 5 & 5 & 5 & 5 \\
\hline & & & Cièncias Fis.Biológicas & 4 & 4 & 4 & 4 \\
\hline & & & \begin{tabular}{|l|} 
Ensino Religioso \\
\end{tabular} & - & - & - & 1 \\
\hline & \multirow{3}{*}{$\begin{array}{l}\text { Oficinas } \\
\text { Curriculares }\end{array}$} & \multicolumn{2}{|c|}{ Orientação para estudo e pesquisa } & 1 & 1 & 1 & - \\
\hline & & $\begin{array}{l}\text { Atividades de } \\
\text { Linguagem e } \\
\text { de Matemática }\end{array}$ & Hora da Leitura & 2 & 2 & 2 & 2 \\
\hline & & \multicolumn{2}{|l|}{ Total } & 30 & 30 & 30 & 30 \\
\hline \multicolumn{8}{|c|}{ Almoço - $12 \mathrm{~h} 20$ as $13 \mathrm{~h} 20$} \\
\hline \multirow{14}{*}{$\begin{array}{l}\text { Tarde } \\
13 \mathrm{~h} 20 \text { as } \\
16 \mathrm{~h} 10\end{array}$} & \multirow{14}{*}{$\begin{array}{l}\text { Oficinas } \\
\text { Curriculares }\end{array}$} & \multirow{3}{*}{$\begin{array}{l}\text { Atividades de } \\
\text { Linguagem e } \\
\text { de Matemática }\end{array}$} & $\begin{array}{l}\text { Experiências } \\
\text { Matemáticas }\end{array}$ & \multirow{3}{*}{5} & \multirow{3}{*}{5} & \multirow{3}{*}{5} & \multirow{3}{*}{5} \\
\hline & & & $\begin{array}{l}\text { Língua Estr.Moderna - } \\
\text { Espanhol* }\end{array}$ & & & & \\
\hline & & & $\begin{array}{l}\text { Informática } \\
\text { Educacional } \\
\end{array}$ & & & & \\
\hline & & \multirow{4}{*}{$\begin{array}{l}\text { Atividades } \\
\text { Artisticas }\end{array}$} & \begin{tabular}{|l|} 
Teatro \\
\end{tabular} & & & & \\
\hline & & & \begin{tabular}{|l|} 
Artes Visuais \\
\end{tabular} & \multirow{3}{*}{3} & \multirow{3}{*}{3} & \multirow{3}{*}{3} & \multirow{3}{*}{3} \\
\hline & & & \begin{tabular}{|l|} 
Música \\
\end{tabular} & & & & \\
\hline & & & Dança & & & & \\
\hline & & \multirow{3}{*}{\begin{tabular}{|l|} 
Atividades \\
Esportivas e \\
Motoras \\
\end{tabular}} & Esporte & & & & \\
\hline & & & \begin{tabular}{|l} 
Ginástica \\
\end{tabular} & 3 & 3 & 3 & 3 \\
\hline & & & Jogo & 3 & 2 & 10 & 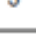 \\
\hline & & \multirow{3}{*}{$\begin{array}{l}\text { Atividades de } \\
\text { Participaçăo } \\
\text { Social }\end{array}$} & $\begin{array}{l}\text { Saúde e Qualidade de } \\
\text { Vida }\end{array}$ & \multirow{3}{*}{4} & \multirow{3}{*}{4} & \multirow{3}{*}{4} & \multirow{3}{*}{4} \\
\hline & & & \begin{tabular}{|l} 
Filosofia \\
\end{tabular} & & & & \\
\hline & & & $\begin{array}{l}\text { Empreendedorismo } \\
\text { Social }\end{array}$ & & & & \\
\hline & & \multicolumn{2}{|l|}{ Total } & 15 & 15 & 15 & 15 \\
\hline Total & & & & 45 & 45 & 45 & 45 \\
\hline
\end{tabular}

*A carga horária de Língua Estrangeira Moderna - Espanhol, quando incluída, será de uma aula semanal.

Fonte: SÃO PAULO. Secretaria da Educação do Estado de São Paulo. CENP. Matriz Curricular da Escola de Tempo Integral. Ensino Fundamental - Ciclo II. In: SE/CENP. Escola de Tempo Integral. Tempo e qualidade, 2007 [apostila]. 
A Proposta das "Escolas de Tempo Integral" (ETI) buscava favorecer a vivência de atividades dinâmicas, contextualizadas, significativas no campo da arte, da leitura, da matemática, do esporte, do convívio social, contribuindo,deste modo, com o processo de avaliação do desempenho escolar do aluno, uma vez que este teria maiores possibilidades de desenvolver suas potencialidades, diversidades, habilidades. Considerava-se o aluno de forma integral, mas sob uma perspectiva vinculada às aprendizagens formais, expressas nos componentes curriculares, uma vez que se trabalhava com a proposta do currículo básico e as "oficinas curriculares", orientação de estudos; atividades artísticas e culturais; atividades desportivas; atividades de integração social e atividades de enriquecimento curricular. Sendo assim, a proposta da ETI era:

[...] valorizar a ação do aluno, deslocando o papel do professor para se tornar o agente de mobilização da capacidade intelectual de quem aprende; incorporar as questões do cotidiano, inserindo conteúdos atuais e contextualizados; recolocar o sentido do erro, transformando-o em fonte de informação para verificar o percurso que o aluno fez (e não o que não fez) e ampliar as práticas de avaliação para que permitam verificar o aluno agindo com os objetos e com seus colegas (SÃO PAULO. Secretaria da Educação do Estado de São Paulo. Política educacional da SEE. Escola de Tempo Integral. Tempo e qualidade - construção de uma proposta, ciclos I e II, 2007, p.11).

Um dos pilares dessa proposta foi o de afirmar-se por meio do convívio diário com as novas informações e mudanças de hábitos dos alunos, já que cada oficina complementava o currículo básico, potencializando talentos e possibilitando a comunicação e a participação do aluno no mundo globalizado (ALMEIDA, 2007).

Ressaltamos, no entanto, que durante o período de implantação da proposta da Escola de Tempo Integral, na rede pública estadual, ocorreram problemas referentes à atribuição 
das aulas para os professores indicados a ministrar aulas nas "oficinas curriculares", isto porque, de acordo com o Decreto n. 37.185/1993, ao fixar o módulo de pessoal das unidades escolares da Secretaria de Estado da Educação, no que se refere aos especialistas de educação do QM (Quadro do Magistério) e do QAE (Quadro de Apoio Pedagógico), regulamentado pela Resolução SE-SP n. 35/2000, dispunha-se que o processo de seleção, escolha e designação de docentes para exercer as funções de Professor coordenador, em seu Artigo $4^{\circ}$., parágrafo $2^{\circ}$., para as aulas das oficinascurriculares, a atribuição deveria ser efetivada obedecendo ao quesito de que: para a disciplina "Empreendedorismo Social" - o docente deverá comprovar a licenciatura plena em Ciências Sociais; e para "Filosofia" - comprovar licenciatura plena em Filosofia.

Tendo em vista a inviabilidade do cumprimento ao dispositivo legal, sobretudo pela falta de docentes licenciados nas referidas disciplinas, assim como, a necessidade de cumprir tais requisitos para o início do ano letivo, as oficinas foram atribuídas aos docentes licenciados em Estudos Sociais, plenificados em História, sob autorização emitida pelas Diretorias Regionais de Ensino de cada Região.

Então, sobre o ensino integral e seus desdobramentos verificamos que o ensino oferecido pela rede pública estadual de São Paulo, entre eles, a Escola de Tempo Integral (ETI),contribuiu para o aprimoramento do processo educacional dos alunos, considerando suas novas concepções e fundamentações pedagógicas, apesar do registro de dificuldades vivenciadas pelas equipes gestora, de professores e comunidade durante o processo de implantação.

\section{O PROGRAMA ENSINO INTEGRAL (PEI)}

No âmbito nacional, historicamente, muitas foram as experiências voltadas para a implantação da Escola de Ensino Integral, destacando-se, por exemplo, a Escola de Ensino Médio Integral, do Estado de Pernambuco concebida pelo Instituto de corresponsabilidade pela Educação - ICE e implantada no Ginásio Pernambucano em 2004. Essa escola foi criada por decreto do presidente provincial José Carlos Mayrink da Silva Ferrão, 
em $1^{\circ}$. de setembro de 1825 (colégio mais antigo do Brasil), com o nome de Liceu Provincial de Pernambuco, também chamado Liceu Pernambucano, funcionando nas dependências do Convento do Carmo, atualmente localizado na rua da Aurora, n. 703, bairro de Santo Amaro, Recife.

Em 2004, o ginásio foi reinaugurado como Centro de Ensino Experimental (CEE), projeto idealizado por um grupo de empresários e educadores e realizado em parceria com o Governo do Estado de Pernambuco, cujo objetivo era dar atendimento ao aluno em tempo integral, treinamento e elevação salarial para os professores, premiação por resultados do aperfeiçoamento da gestão, controle social e integração comunitária. ${ }^{2} \quad$ Tendo o olhar voltado para as exigências do mundo globalizado e com base no aperfeiçoamento da política educacional implantada em São Paulo, a Secretaria da Educação estruturou, desde 2011, suas ações e prioridades no Programa Educação Compromisso de São Paulo, instituído pelo Decreto n. 57.571, de 2 de dezembro de 2011, tendo como um de seus pilares, o lançamento das bases de um novo modelo de escola e de um regime mais atraente para a carreira do magistério.

Nessa perspectiva, o Programa Ensino Integral instituído pela Lei Complementar n.1.164, de 4 de janeiro de 2012, alterada pela Lei Complementar n. 1.191, de 28 de dezembro de 2012 foi implantado no Estado de São Paulo, segundo o modelo do Ginásio de Pernambuco, não obstante os necessários ajustes, principalmente aqueles relacionados aos critérios de inclusão das escolas, composição da equipe escolar, avaliação de desempenho da equipe escolar, formação e acompanhamento, gestão e, finalmente, a avaliação diagnóstica dos alunos, tendo como referência o currículo do Estado de São Paulo.

Inicialmente, o programa atendia a 16 escolas de Ensino Médio. No ano de 2013, ocorreu a primeira expansão do programa, passando a atender também ao ensino fundamental (anos finais), englobando 22 escolas do ensino fundamental (anos

2 As informações referentes ao Ginásio Pernambucano foram fornecidas por Lúcia Gaspar,bibliotecária da Fundação Joaquim Nabuco, Recife. Disponível em: www.fundaj.gov.brAcesso em: 8 set. 2016. 
finais), 29 do ensino médio, e mais duas escolas híbridas, assim denominadas porque atendiam simultaneamente a alunos do ensino fundamental (anos finais) e do ensino médio, perfazendo um total de 69 escolas.

Em 2014, o Programa Ensino Integral passou por novo processo de expansão atendendo a 39 escolas de ensino fundamental (anos finais), 26 escolas do ensino médio, e 48 escolas de ensino fundamental e médio, totalizando 182 unidades escolares. Consideradas as 69 já implantadas no ano anterior, com previsão para que até o ano de 2018 o programa seja implantado em mil escolas da rede pública estadual(SÃO PAULO. Secretaria da Educação do Estado de São Paulo. Programa Ensino Integral Escola de Tempo Integral. Diretrizes do Programa Ensino Integral, 2014, p. 5).

Como política pública, essa modalidade objetivava oferecer aos jovens que ingressavam nessas escolas, além da formação acadêmica necessária ao seu desenvolvimento intelectual, a ampliação das perspectivas de autorrealização e exercício para uma cidadania autônoma, solidária e competente, permitindo-lhes protagonizar sua história de vida.

Aos docentes e equipes técnicas possibilitou condições diferenciadas de trabalho para que, em regime de dedicação plena e integral, pudessem consolidar as diretrizes educacionais do programa, ao mesmo tempo, sedimentar as possibilidades previstas para a sua expansão, critério esse não utilizado para os docentes e gestores da Escola de Tempo Integral (ETI).Cabe, então, refletir a respeito de qual é a real necessidade de uma organização curricular diferenciada, uma vez que se tem por objetivo oferecer ao aluno uma educação integral?

Dessa forma, para melhor esclarecer, apresentamos, a seguir, no Quadro 3, a matriz curricular do Programa Ensino Integral do Ensino Fundamental - anos finais (PEI) no qual observamos divergências em relação à organização existente entre uma e outra matriz curricular. Considerando a discussão pautada no ensino integral, cujo objetivo é a formação global do indivíduo. 
Quadro 3.Matriz Curricular do Ensino Fundamental Integral - Anos Finais (PEI)

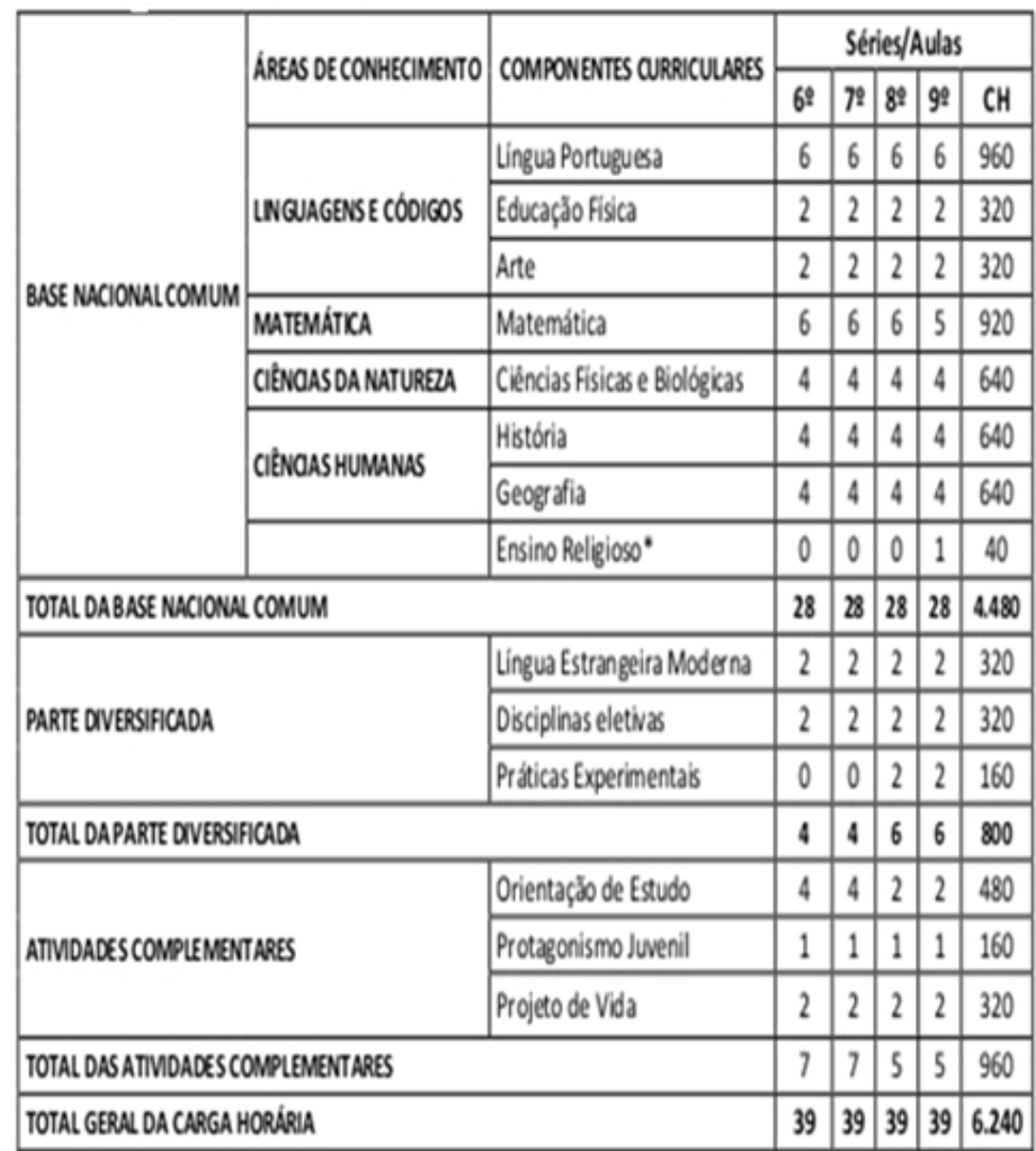

Fonte: SÃO PAULO. Secretaria da Educação do Estado de São Paulo. Diretrizes do Programa Ensino Integral. In: Secretaria da Educação do Estado de São Paulo. Programa Ensino Integral-Escola de Tempo Integral. Informações básicas,abril, 2014. 


\section{A ORGANIZAÇÃO CURRICULAR: ALGUNS COMPARATIVOS ENTRE ETI E PEI}

Com base na organização curricular da Escola de Tempo Integral Ciclos I e II (ETI) e na matriz curricular do Programa Ensino Integral Ensino Fundamental - anos finais (PEI), podemos observar que entre as matrizes curriculares no que se refere à base nacional comum, ambas seguem o estabelecido por Lei, conforme demonstrado nos quadros já apresentados, todavia, verificamos que, quanto à parte diversificada, há variáveis entre uma e outra. Percebemos ainda que a Proposta da "Escola de Tempo Integral" (ETI) busca favorecer a vivência de atividades dinâmicas, contextualizadas, significativas no campo da arte, da leitura, da matemática, do esporte, do convívio social, contribuindo, assim, com o processo de avaliação do desempenho escolar do aluno, uma vez que este terá maiores possibilidades de desenvolver suas potencialidades, suas diversidades, suas habilidades, primando pelo desenvolvimento do aluno de forma integral sob uma perspectiva vinculada às aprendizagens formais expressas nos componentes curriculares.

O Programa Ensino Integral (PEI)traz em sua parte diversificada uma proposta que conduz o aluno à elaboração e construção de seu projeto de vida, evidenciando a importância do protagonismo juvenil, estimulando o jovem a ser o autor de sua própria história, desenvolvendo ações que o levem a tornar-se autônomo, solidário e competente.

Para tanto, traz em seu modelo de gestão do ensino integral:

[...] premissas que ao se integrarem aos princípios educativos do modelo pedagógico articulam às ações educativas desenvolvidas na escola. Seus instrumentos de gestão permitem acompanhar e monitorar o trabalho pedagógico e formular planos de formação continuada para a equipe escolar. Isto é, a escola diante de suas finalidades educacionais organiza-se numa gestão integrada de seus diferentes segmentos e contributos de todos, seja individualmente ou coletivamente. A gestão do modelo pedagógico ao estabelecer os acordos quanto aos resultados pretendidos e as suas 
estratégias permite, após a análise de indicadores, a correção dos caminhos perseguidos para a qualidade do processo de ensino-aprendizagem (SÃO PAULO. Secretaria da Educação do Estado de São Paulo. Diretrizes do Programa Ensino Integral. Escola de Tempo Integral, 2014, p. 33).

Registra-se, pois, que embora as Escolas de Tempo Integral (ETI) e o Programa Ensino Integral (PEI) tenham como ponto de convergência o princípio do aprimoramento educacional, visando proporcionar às crianças e aos jovens maior tempo de permanência na escola e um ensino com qualidade, verifica-se, no entanto, notórios pontos diferenciais entre as propostas.

Desta maneira, passamos a demonstrar, por meio de representação gráfica, a sistematização das duas propostas, para efeito comparativo. Na Figura 1, sinaliza-se a sistematização da proposta de Escola de Tempo Integral (ETI) e, mais adiante, na Figura 2, a sistematização do Programa Ensino Integral (PEI).

Figura 1. Sistematização da Proposta da Escola de Tempo Integral (ETI)

OBJETIVO DA ESCOLA DE TEMPO INTEGRAL (ETI)

\section{DESENVOLVIMENTO DA CRIANCCA / JOVEM EM TODAS AS DIMENSŐES}

CURRICULO

BÁSICO - BASE

NACIONAL

COMUM E PARTE

DIVERSIFICADA

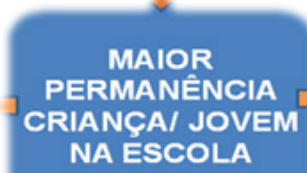

ENVOLVIMENTO

GESTOR * DISCENTE* PESSOAL DE APOIO* PAIS * COMUNIDADE

Conforme já mencionado, a Escola de Tempo Integral (ETI) tem o seu foco pedagógico nas disciplinas da Base Nacional 
Comum e a Parte Diversificada, com ênfase nas Oficinas Curriculares que envolvem atividades de linguagem e de matemática, atividades artísticas, atividades esportivas e motoras, atividades de participação social e orientação para estudos e pesquisa, cabendo a cada uma delas complementar o currículo básico. Tem como expectativa que por meio do convívio diário de mudanças de hábitos seja possível potencializar o talento dos alunos com o oferecimento de informações que estimulem a comunicação e a participação com o mundo globalizado, favorecendo sua condição sociocultural e, por decorrência, afastando-os da "marginalidade".

O Programa Ensino Integral (PEI) tenciona criar condições ao aluno para que desenvolva suas potencialidades e que se torne um jovem autônomo, solidário e competente, sobretudo, mediante o oferecimento da excelência acadêmica e de condições ao desenvolvimento de seu projeto de vida a que se torne protagonista de sua história. O Programa não deixa de enfatizar a importância das disciplinas da Base Nacional Comum, porém traz como parte diversificada o conjunto das disciplinas eletivas que representam uma estratégia para a ampliação do universo cultural do estudante, conforme apresentamos na Figura 2.

Figura 2. Sistematização do Programa Ensino Integral

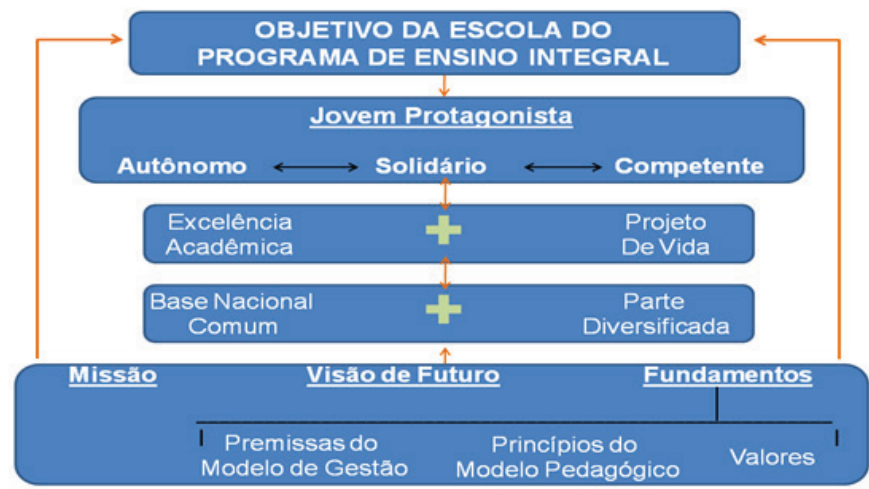

Fonte:SÃO PAULO. Secretaria da Educação do Estado de São Paulo. Programa Ensino Integral. Escola de Tempo Integral. Diretrizes do Programa Ensino Integral, abril 2014.Material disponibilizado no treinamento para gestores do Programa Ensino Integral realizado em Serra Negra,São Paulo, no período de 2 a 5 de dezembro de 2014 . 
Por se tratar de uma nova proposta e de um novo programa de ensino no campo educacional, no qual o processo de aprendizagem é efetivado por meio de ações e práticas reformuladas que buscam tornar o espaço escolar mais atrativo para o aluno, como também, o processo de aprendizagem mais significativo, destaca-se a necessidade de garantir a qualidade do ensino e a formação do indivíduo, de maneira que cada um possa desenvolver suas habilidades e competências, considerando o atual cenário educacional.

\section{CONSIDERAÇÕES FINAIS}

Partindo-se da premissa que o foco de nossa discussão é o de oferecer ao aluno uma escola onde possa desfrutar não só o ensino formal (disciplinas da Base Nacional Comum), como também desenvolver suas potencialidades no campo sociocultural, de formar um indivíduo por inteiro, com fundamentos nas discussões teóricas aqui apresentadas sobre educação integral e considerando as propostas pedagógicas elaboradas pela Escola de Tempo Integral (ETI) e pelo Programa Ensino Integral (PEI), bem como, as reflexões aqui expostas, questiona-se a existência da dualidade curricular e pedagógica entre os modelos que constituem a Educação Integral, uma vez que as discussões teóricas aqui exibidasacerca do tema remete-nos a uma visão de educação global, considerando a importância de uma revisão no sentido do real entendimento conceitual entre ambos os programas diante do que entendemos por Educação Integral.

\section{REFERÊNCIAS}

ALMEIDA, Denise de. Escola de tempo integral: uma escola diferente ou a escola que faz a diferença. Dissertação (Mestrado) - Universidade Metodista de São Paulo, Faculdade de Educação e Letras, Pós-Graduação em Educação. São Bernardo do Campo, 2007.

ANTUNES, Ângela; PADILHA, Paulo Roberto. Educação Cidadã, Educação Integral: fundamentos e práticas. São Paulo: Instituto Paulo Freire, 2010 (série Educação Cidadã, n. 6).

DEWEY, John.Democracia e Educação, 3.ed.São Paulo:Nacional, 1959.

GUARÁ, Isa Maria F. Rosa. É imprescindivel educar integralmente. Cadernos CENPEC, n. 2, p.15-24, 2006. 
MIGNOT, Ana Chrystina V. Escolas na vitrine: centros integrados de educação pública (1983-1987). Revista Estudos Avançados, v.15, n.42, mai./ago.2001. PACHECO, J. Escola da Ponte em Portugal. In: CONGRESSO INTERNACIONAL DE EDUCAÇÃO, ESCOLA DE TEMPO INTEGRAL. 2006. Anais... São Paulo, Secretaria de Estado de São Paulo, 2006.

PARO, Vitor Henrique; FERRETI, Celso João;VIANA,Cláudia Pereira; SOUZA, Denise Trento Rebello de. A Escola de Tempo Integral: desafio para o Ensino Público. São Paulo: Cortez, 1988.

RIBEIRO, A. I. M. Mulheres educadas na colônia. In: LOPES, E. M. T.; FARIA, L. M. F.; VEIGA, C. G.(Orgs). 500 anos de educação no Brasil. Belo Horizonte: Autêntica, 2000.

SÃO PAULO. Secretaria da Educação do Estado de São Paulo. Coordenadoria de Estudos e Normas Pedagógicas. Escola de Tempo Integral. Tempo e qualidade. Construção de uma proposta ciclos I e II. São Paulo: Secretaria da Educação do Estado de São Paulo/CENP, 2007.

SÃO PAULO. Secretaria da Educação do Estado de São Paulo. CENP. Matriz Curricular da Escola de Tempo Integral. Ensino Fundamental - Ciclo I. In: SE/CENP. Escola de Tempo Integral.Tempo e qualidade.Construção de uma proposta Ciclos I e II, 2007 [apostila].

SÃO PAULO. Secretaria da Educação do Estado de São Paulo. CENP. Matriz Curricular da Escola de Tempo Integral. Ensino Fundamental - Ciclo II. In: SE/CENP. Escola de Tempo Integral.Tempo e qualidade.Construção de uma proposta Ciclos I e II, 2007 [apostila].

SÃO PAULO. Secretaria da Educação do Estado de São Paulo. Diretrizes do Programa Ensino Integral. In: Secretaria da Educação do Estado de São Paulo. Programa Ensino Integral- Escola de Tempo Integral. Informações básicas, abr.2014.

SÃO PAULO. Governo do Estado de São Paulo. Decreto n. 59.354,de 15 de julho de 2013. Dispõe sobre o Programa Ensino Integral de que trata a Lei Complementar n. 1.164, de 4 de janeiro de 2012, alterada pela Lei Complementar n. 1.191, de 28 de dezembro de 2012. São Paulo. Poder executivo, 15 de julho de 2013.

SÃO PAULO. Governo do Estado de São Paulo. Decreto n.37.185, de 5 de agosto de 1993. Fixa o módulo de pessoal das unidades da Secretaria da Educação e dá outras providências correlatas. São Paulo. Poder executivo, 5 de agosto de 1993.

SÃO PAULO. Secretaria da Educação do Estado de São Paulo. Resolução SE n. 35/2000. Dispõe sobre o processo de seleção, escolha e designação de docente para exercer as funções de Professor Coordenador, em escolas da rede estadual de ensino e dá providências correlatas. São Paulo: Secretaria da Educação do Estado de São Paulo, 2000.

SÃO PAULO. Governo do Estado de São Paulo.Decreto n. 57.571, de 2 de dezembro de 2011. Institui junto à Secretaria da Educação o Programa Educação - Compromisso de São Paulo. São Paulo: Governo do Estado 
de São Paulo, 2011.

TEIXEIRA, Anísio. Centro Educacional Carneiro Ribeiro. Revista Brasileira de Estudos Pedagógicos. Rio de Janeiro, v. 31, n. 73, p. 78-84, jan./mar. 1959.

TEIXEIRA, Anísio. Educação não é privilégio, 6.ed. Rio de Janeiro: Editora UFRJ, 1994.

REFERÊNCIA ELETRÔNICA

FUNDAJ. Fundação Joaquim Nabuco. Disponível em: www.fundaj.gov.brAcesso em: 5 jan.2017.

\section{SOBRE A AUTORA}

Denise de Almeida Ostler. Bacharel em Comunicação social (RP), pela Universidade Católica de Santos. Pedagoga em Educação Especial (DI), pela Universidade Metodista de Piracicaba.Psicopedagoga, Pós-graduação (Lato sensu), Faculdade Dom Domenico. Mestre e Doutora em Educação, pela Universidade Metodista de São Paulo. 